\title{
Coesão de grupo e liderança do treinador em função do nível competitivo das equipes: um estudo no contexto do futsal paranaense
}

\section{Group cohesion and coach leadership based on the competitive level of teams in the context of Paraná's indoor soccer}

\section{José Roberto Andrade do Nascimento Junior}

Lenamar Fiorese Vieira

Resumo - Este estudo analisou o nível de coesão de grupo e o estilo de liderança dos treinadores de equipes de futsal do estado do Paraná. Participaram da pesquisa, 122 atletas de quatro equipes da Liga Nacional e quatro do Campeonato Paranaense 2011 e oito técnicos, totalizando 130 sujeitos. Como instrumentos, foram utilizados o Questionário de Ambiente de Grupo, a Escala de Liderança no Desporto e uma entrevista semiestruturada. Para a análise dos dados, aplicaram-se o teste Kolmogorov-Smirnov, o alfa de Cronbach, o "U" de Mann-Whitney ( $\mathrm{p}<0,05)$ e a Análise de Conteúdo. Os resultados evidenciaram que as equipes participantes do Campeonato Estadual apresentaram maior nível de coesão em relação às equipes da Liga Nacional; os técnicos das equipes do Campeonato Estadual forneceram mais instruções, reforço e suporte social aos atletas, além de apresentarem estilo mais democrático se comparados aos técnicos da Liga Nacional - características também encontradas na análise qualitativa. Concluiu-se que o nível competitivo (estadual/ nacional) das equipes constituiu um elemento interveniente no nível de coesão e no estilo de liderança dos técnicos.

Palavras-chave: Ambiente de grupo; Líder; Esporte.

Abstract - The objective of the present study was to analyze the level of group cohesion and coach leadership style of five-a-side soccer teams from the state of Paraná. Participants consisted of 122 athletes of four teams competing at the National League and four teams competing at the Paraná State Championship in 2011, as well as eight coaches. The following instruments were used: the Group Environment Questionnaire, the Leadership Scale for Sports, and a semi-structured interview. Data analysis was performed using the Kolmogorov-Smirnov test, Cronbach's alpha, Mann-Whitney " $U$ " test $(p<0.05)$, and categorical analysis. The results demonstrated that the State Championship teams showed higher levels of group cohesion when compared to the National League teams; the coaches of the State Championship teams provided more instructions, reinforcement, and social support to athletes, in addition to showing a more democratic style when compared to the National League coaches - these characteristics were also found in the qualitative analysis. We concluded that the performance level (state/national) of the five-a-side soccer teams had an influence on the cohesion level and coaches' leadership style.

Key words: Group Environment; Leader; Sport.
1 Universidade Estadual de Maringá. Programa de Pós-Graduação Associado em Educação Física da Universidade Estadual de Maringá e Universidade Estadual de Londrina. Maringá, PR. Brasil.

Recebido em 10/05/12 Revisado em 15/07/12 Aprovado em 24/07/12 


\section{INTRODUÇÃO}

Pesquisas recentes na área da Psicologia do Esporte têm apontado que variáveis como o nível de coesão de grupo e o estilo de liderança do técnico são elementos que podem influenciar o desempenho dos atletas e o sucesso de uma equipe esportiva ${ }^{1,2}$, visto que as relações técnico-atleta e atleta-equipe são essenciais para o alcance das metas e dos objetivos de uma equipe ${ }^{3}$.

A coesão de grupo é caracterizada como um processo dinâmico que tem como finalidade favorecer a união de um grupo para o alcance de suas metas e satisfação das necessidades afetivas dos membros ${ }^{1,4}$. No entanto, alguns fatores podem interferir no ambiente e no desempenho de uma equipe $^{5}$, como o estilo de liderança do treinador, visto que um bom líder esportivo pode oferecer um bom suporte aos seus atletas, fornecendo estratégias e recursos para o desenvolvimento da coesão de grupo e para o alcance das metas da equipes ${ }^{6,7}$.

Embora já tenham sido realizados estudos relacionando a liderança do treinador e o nível de coesão de grupo de equipes esportivas ${ }^{8-12}$, a pesquisa bibliográfica não identificou trabalhos que tenham comparado os níveis de coesão de grupo e o estilo de liderança de treinadores em função do nível de desempenho de equipes profissionais, sendo esta uma lacuna que o presente estudo pretende explorar.

De acordo com o modelo conceitual de coesão no esporte ${ }^{13}$, quanto maior o nível de desempenho de uma equipe, mais autocrático é o estilo do treinador ${ }^{8}$ e maior é a coesão para a tarefa dos atletas ${ }^{14}$. Por outro lado, em equipes de nível inferior prevalecem treinadores mais democráticos e maiores percepções de coesão social, além da coesão para a tarefa ${ }^{15}$. No entanto, o presente estudo pretende avançar ao comparar o nível de coesão de grupo e o estilo de liderança de técnicos de equipes profissionais de futsal de diferentes níveis competitivos (estadual/nacional), além da utilização de métodos de análise quantitativa e qualitativa, o que proporciona uma maior profundidade na abordagem da temática. Os resultados desta pesquisa poderão contribuir para que técnicos possam adequar seu estilo de liderança de acordo com o nível competitivo de suas equipes, favorecendo, assim, o desenvolvimento da coesão de grupo e o alcance das metas.

Diante disso, esta pesquisa objetivou analisar o nível de coesão de grupo e o estilo de liderança dos treinadores de equipes profissionais de futsal do estado do Paraná-Brasil. O interesse específico residiu em comparar o nível de coesão de grupo e o estilo de liderança dos técnicos, considerando o nível competitivo das equipes (Liga Nacional e Campeonato Paranaense).

\section{PROCEDIMENTOS METODOLÓGICOS}

\section{Participantes}

Participaram do estudo 122 atletas - integrantes das quatro equipes paranaenses da Liga Nacional de Futsal 2011 e das quatro equipes mais bem classificadas do Campeonato Paranaense 2011, excluindo as participantes 
da Liga Nacional - e oito técnicos, totalizando 130 sujeitos. O critério para a escolha da amostra - dividida em dois grupos (1) e (2) - foi o nível de desempenho esportivo (ranking no Campeonato Paranaense 2011 e participação na Liga Nacional de Futsal 2011). A Liga Nacional é considerada a principal e mais importante competição brasileira de futsal, enquanto o Campeonato Paranaense é considerado como um dos campeonatos estaduais mais competitivos do país, entretanto, de nível inferior à Liga Nacional.

Grupo 1 - Atletas (65) e técnicos (4) das quatro equipes paranaenses participantes da Liga Nacional de Futsal $2011(\mathrm{n}=69)$.

Grupo 2 - Atletas (57) e técnicos (4) das quatro melhores equipes do Campeonato Paranaense de Futsal $2011(\mathrm{n}=61)$.

A seleção para a entrevista foi não probabilística de conveniência, com amostra constituída por três atletas de cada equipe dos dois estratos (20\% dos atletas de cada equipe), além da inclusão de todos os técnicos. No entanto, um dos técnicos das equipes participantes da Liga Nacional (Grupo 1) não aceitou participar da entrevista. Assim, a amostra selecionada para a entrevista foi de 31 sujeitos (24 atletas e 7 técnicos).

\section{Instrumentos}

Para identificar o nível de coesão das equipes de futsal, foi utilizado o Questionário de Ambiente de Grupo (QAG), uma adaptação e validação para a língua portuguesa ${ }^{16}$ do Group Environment Questionnaire ${ }^{13}$, revisado e modificado por Eys et al. ${ }^{17}$. Tal questionário é constituído por 16 itens que avaliam a coesão de grupo em equipes esportivas e são distribuídos em quatro dimensões: 1) Integração no Grupo-Tarefa, 2) Integração no Grupo-Social, 3) Atração Individual para o Grupo-Tarefa e 4) Atração Individual para o Grupo-Social. As respostas são dadas em uma escala do tipo likert de nove pontos que variam de "discordo totalmente" (1) a "concordo totalmente" (9). As pontuações mais altas significam valores mais elevados de coesão em cada uma das dimensões. O alfa de Cronbach para as dimensões de coesão de grupo variou de $\alpha=0,70$ a $\alpha=0,83$.

A fim de verificar o estilo de liderança dos técnicos, foi utilizada a Escala de Liderança no Desporto (ELD) ${ }^{18}$, adaptada e validada para a língua portuguesa por Serpa et al. ${ }^{19}$. Esse instrumento é constituído por 40 itens que descrevem cada tipo de comportamento do líder esportivo, os quais são agrupados nas cinco dimensões seguintes: Treino-Instrução, Suporte Social, Reforço, Democrático e Autocrático. A ELD é composta por três versões. Uma dessas versões aborda a percepção do técnico de seu próprio comportamento (versão autopercepção). A segunda refere-se à percepção que os atletas têm do comportamento do técnico (versão percepção) e a última mede a preferência dos atletas pelo comportamento do técnico (versão preferência). Os itens são respondidos em uma escala do tipo likert de cinco pontos, variando de "nunca" (1) a "sempre" (5). As pontuações mais altas significam valores mais elevados em cada uma das dimensões. $\mathrm{O}$ alfa de Cronbach para as dimensões de liderança do técnico variou de $\alpha=0,50$ a $\alpha=0,77$. 
A análise qualitativa foi realizada com base num roteiro de entrevista semiestruturada de acordo com os elementos do modelo conceitual de coesão no esporte ${ }^{13} \mathrm{e}$ do modelo multidimensional de liderança no esporte ${ }^{6}$. A entrevista semiestruturada teve como objetivo verificar as características da coesão de grupo e do estilo de liderança dos técnicos das equipes (Grupos 1 e 2).

O roteiro de entrevista da para verificar a percepção de coesão foi baseado nos seguintes indicadores:

- Integração no Grupo-Tarefa: Semelhança e proximidade da equipe quanto às tarefas a realizar (União da equipe, responsabilidade por derrota/desempenho ruim, resolução de problemas das tarefas, comunicação em treinos e jogos);

- Integração no Grupo-Social: Semelhança e proximidade no interior da equipe como um todo, enquanto unidade social (Festas em grupo, atividades em grupo fora da equipe e após a temporada);

- Atração Individual para o Grupo-Tarefa: Envolvimento pessoal com as tarefas, produtividade, metas e objetivos do grupo (Quantidade de tempo jogado, vontade de vencer da equipe, estilo de jogo da equipe, desempenho pessoal);

- Atração Individual para o Grupo-Social: Envolvimento pessoal, aceitação e interação social com o grupo (Amizade com outros atletas, gosto pelas atividades sociais da equipe, pessoas importantes).

- O roteiro de entrevista da para verificar a as características do estilo de liderança dos treinadores das equipes de futsal foi baseado nos seguintes indicadores:

- Características do Líder: Conhecimento sobre o contexto esportivo, sobre as exigências da modalidade e pela personalidade e experiência (Tempo de prática, tempo na equipe, títulos, aceita opinião dos atletas, fornece apoio, suporte, reforço, foi atleta, formação profissional);

- Características da Situação: Fatores ambientais que podem influenciar e afetar o comportamento do treinador (Normas da equipe, forma de disputa da competição, objetivos, tradições, ambiente de treino, condição física e técnica dos atletas, cultura organizacional e estrutura);

- Características dos Atletas: Maturidade, personalidade, capacidades técnicas e físicas, experiência no esporte, motivação, idade e gênero (Tempo de prática, tempo na equipe, satisfação com o papel e desempenho, expectativas, envolvimento com a equipe).

O roteiro-piloto da entrevista foi previamente analisado por especialistas da área, aos quais competiu comprovar a validade do instrumento, ou seja, se nenhum dos elementos da coesão de grupo e da liderança do técnico seria desconsiderado, se os dados necessários à pesquisa seriam coletados. Coube, ainda, aos especialistas confirmar a operatividade da entrevista, observando se o vocabulário estava acessível aos sujeitos (clareza), bem como o significado das questões ${ }^{20}$. 


\section{Coleta de dados}

Inicialmente, os pesquisadores contataram a diretoria da Federação Paranaense de Futsal, com o intuito de esclarecer os objetivos e os procedimentos que seriam utilizados durante a pesquisa. Após a autorização do diretor da Federação Paranaense de Futsal, o estudo foi submetido ao Comitê Permanente de Ética em Pesquisa com Seres Humanos (Copep) da Universidade Estadual de Maringá, o qual concedeu a aprovação sob o Parecer $n^{\circ} 336 / 2011$. A seguir, foram agendadas datas para a assinatura do Termo de Consentimento Livre e Esclarecido pelos atletas e técnicos. Os testes psicométricos foram aplicados em dias e horários disponibilizados pelos jogadores e pelos técnicos. A entrevista semiestruturada foi realizada pelos pesquisadores, individualmente, em um local privativo, com duração média de 30 minutos cada. Foi solicitada a permissão para a gravação da entrevista para posterior transcrição dos dados na íntegra. Os depoimentos dos atletas foram colhidos a partir de um roteiro pré-estabelecido para a entrevista.

\section{Análise dos dados}

Para a análise dos dados quantitativos, foi realizada a análise da distribuição dos dados com base no teste de Kolmogorov-Smirnov. Como os dados não apresentaram distribuição normal, foram utilizados Mediana (Md) e Quartis (Q1; Q3) para a caracterização dos resultados. Para comparar o nível de coesão e o estilo de liderança do técnico em função do nível de desempenho das equipes, foi utilizado o teste "U" de Mann-Whitney. A avaliação da consistência interna dos instrumentos foi realizada com base no alfa de Cronbach. O nível de significância adotado foi $\mathrm{p}<0,05$.

A análise qualitativa dos dados foi feita mediante a análise de conteúdo do tipo categorial, com método de análise temática, seguindo os passos de pré-análise, exploração do material e tratamento dos resultados ${ }^{20}$. As categorias foram previamente definidas por meio da matriz de análise, baseada nos modelos teóricos de suporte da pesquisa. Além disso, foram feitos recortes dos depoimentos dos atletas e técnicos. Com o intuito de manter sigilo quanto à identificação dos depoimentos, os atletas e técnicos foram codificados de acordo com a competição de que suas equipes participavam. Os atletas das equipes classificadas para a Liga Nacional de Futsal receberam o código ALN (ALN1, ALN2...) e os jogadores do Campeonato Paranaense de Futsal receberam o código ACP (ACP1, ACP2...). Os técnicos da Liga Nacional foram identificados com o código TLN (TLN1, TLN2...) e os técnicos do Campeonato Paranaense foram denominados TCP (TCP1, TCP2...).

\section{RESULTADOS}

Verificou-se que tanto os atletas da Liga Nacional quanto os jogadores do Campeonato Estadual (Paranaense) apresentaram mediana da idade entre $25,0(22,0 ; 27,0)$ e $26,0(21,0 ; 28,0)$ anos, respectivamente. No entanto, 
notou-se, na Tabela 1 , que os atletas que disputavam a competição nacional iniciaram a prática do futsal ( $\mathrm{Md}=7,0$ anos) e participaram da primeira competição ( $\mathrm{Md}=9,0$ anos) antes dos atletas da competição estadual ( $\mathrm{Md}$ $=9,0$ anos $/ 11,0$ anos $)(\mathrm{p}<0,05)$. Em relação ao tempo semanal dedicado à prática do esporte, as equipes da Liga Nacional apresentaram mais horas de treino por semana ( $\mathrm{Md}=11,0$ horas) que as equipes do Campeonato Paranaense ( $\mathrm{Md}=9,0$ horas) $(\mathrm{p}=0,001)$.

Tabela 1. Comparação do perfil dos atletas e do nível de coesão de grupo das equipes de futsal do estado do Paraná em função do nível de disputa.

\begin{tabular}{lccccc}
\hline VARIÁVEIS & $\begin{array}{c}\text { Liga Nacional } \\
(\mathrm{n}=65)\end{array}$ & $\begin{array}{c}\text { Campeonato } \\
\text { Paranaense } \\
(\mathrm{n}=57)\end{array}$ & $\mathrm{p}$ & $\begin{array}{c}\text { Teste } \\
\text { "U" }\end{array}$ \\
\cline { 2 - 3 } & $\mathrm{Md}(\mathrm{Q} 1 ; \mathrm{Q} 3)$ & $\mathrm{Md}(\mathrm{Q} 1 ; \mathrm{Q} 3)$ & & \\
\hline Idade (anos) & $25,0(22,0 ; 27,0)$ & $\begin{array}{c}26,0(21,0 ; 28,0) \\
\text { Início da prática (anos) }\end{array}$ & 0,402 & 1689,50 \\
\hline Primeira competição (anos) & $9,0(6,0 ; 10,0)$ & $9,0(7,0 ; 12,0)$ & $0,047^{*}$ & 1475,50 \\
\hline Tempo na equipe atual (meses) & $6,0(3,5 ; 12,0)$ & $11,0(8,5 ; 14,0)$ & $0,024^{*}$ & 1414,00 \\
\hline Treinos por semana (horas) & $11,0(10,0 ; 11,0)$ & $\begin{array}{c}12,0(5,0 ; 17,0) \\
\text { Horas por treino }\end{array}$ & 0,209 & 1609,00 \\
\hline Coesão de grupo & $2,0(2,0 ; 2,0)$ & $2,0(2,0 ; 2,0)$ & 0,286 & 1820,00 \\
\hline Integração no Grupo-Tarefa & $7,4(6,6 ; 8,1)$ & $8,2(7,6 ; 8,8)$ & $0,001^{*}$ & 1050,50 \\
\hline Integração no Grupo-Social & $5,5(4,8 ; 7,0)$ & $6,3(4,8 ; 7,3)$ & 0,171 & 1586,00 \\
\hline $\begin{array}{l}\text { Atração Individual para o } \\
\text { Grupo-Tarefa }\end{array}$ & $8,0(7,3 ; 8,3)$ & $8,3(7,7 ; 9,0)$ & $0,001^{*}$ & 1208,50 \\
\hline $\begin{array}{l}\text { Atração Individual para o } \\
\text { Grupo-Social }\end{array}$ & $6,5(5,8 ; 7,3)$ & $7,5(6,8 ; 8,3)$ & $0,001^{*}$ & 1011,50 \\
\hline
\end{tabular}

*Diferença significativa: $p<0,05$.

Ao analisar o nível de coesão de grupo (Tabela 1), observou-se diferença estatisticamente significativa entre as equipes que competem na Liga Nacional e as do Campeonato Estadual nas dimensões Integração no Grupo-Tarefa ( $\mathrm{p}=0,001)$ e Atração Individual para o Grupo-Tarefa ( $\mathrm{p}=$ 0,001 ), evidenciando que os atletas que disputavam o Campeonato Paranaense apresentaram maior nível de coesão para a tarefa. Esse resultado é destacado pelo depoimento do atleta ACP9: “A união em termos gerais é boa. Todos pensam iguais, têm o objetivo final de ser campeão, então é boa. A amizade é boa, têm muitos que se conhecem há alguns anos já. Então isso também ajuda, facilita".

Notou-se diferença estatisticamente significativa também na dimensão Atração Individual para o Grupo-Social $(\mathrm{p}=0,001)$, mostrando que os atletas participantes do Campeonato Paranaense apresentaram maior atração individual para os aspectos sociais do grupo. Essa diferença é ressaltada na fala de um dos técnicos das equipes da Liga Nacional: "O tempo, às vezes, é um fator de dificuldade, de a gente ter esse encontro, porque a gente passa muito tempo viajando, confinado, e aí no período que a gente tem nossa folga por uma questão até pessoal, normalmente, o atleta quer estar com a família, enfim, esse tempo normalmente é dedicado pra essas pessoas, então a gente, às vezes, tem 
dificuldade de se encontrar fora de quadra. Sempre que há uma oportunidade a gente costuma jantar com a diretoria ou entre nós mesmos, mas não éum fato que se repete com frequência em função desses problemas de confinamento. A gente já tem um nível de convivência muito grande, então é legal que em um momento de folga você procure outras pessoas, outras amizades ou até mesmo a família pra poder ter esse momento de liberdade pessoal (TLN1)".

Outro elemento enfatizado pelos atletas das equipes participantes apenas do Campeonato Paranaense foi a importância da convivência do grupo fora de quadra, apontada como um fator que contribui para o alcance das metas da equipe, como assinala o jogador ACP7 em seu depoimento: " $A$ gente sempre está junto, fora de quadra também, até porque a gente convive diariamente na casa do atleta, então tem um convívio muito próximo, a gente faz atividades também fora daqui... um jantar, um churrasco, o que ajuda a gente a se conhecer melhor até para melhorar o entrosamento no jogo".

Nesse contexto, a caracterização da percepção de coesão de grupo das equipes do Campeonato Estadual (Paranaense) é apresentada no Quadro 1.

Quadro 1. Caracterização do nível de coesão de grupo das equipes de futsal participantes do Campeonato Paranaense.

\begin{tabular}{|l|l|}
\hline $\begin{array}{l}\text { Dimensões de coesão } \\
\text { de grupo }\end{array}$ & Características \\
\hline $\begin{array}{l}\text { Integração no Grupo- } \\
\text {-Tarefa }\end{array}$ & $\begin{array}{l}\text { - Atletas focados nos mesmos objetivos. } \\
\text { - Trabalho em grupo para o alcance das metas. } \\
\text { - Comemoração de gols em grupo e com a comissão técnica. } \\
\text { - Divisão das tarefas entre os atletas. } \\
\text { - Divisão da responsabilidade por vitórias e derrotas. }\end{array}$ \\
\hline $\begin{array}{l}\text { Integração no Grupo- } \\
\text {-Social }\end{array}$ & $\begin{array}{l}\text { - Participação em atividade fora de quadra (churrascos, jantares). } \\
\text { - Clima saudável e descontraído da equipe. } \\
\text { - Brincadeiras durante os treinos e as viagens. }\end{array}$ \\
\hline $\begin{array}{l}\text { Atração Individual para } \\
\text { o Grupo-Tarefa }\end{array}$ & $\begin{array}{l}\text { - Convivência em família da equipe dentro e fora de quadra. } \\
\text { - Competições a serem disputadas. } \\
\text { - Contato e confiança com o treinador. } \\
\text { - Vontade de vencer da equipe. }\end{array}$ \\
\hline $\begin{array}{l}\text { Atração Individual para } \\
\text { o Grupo-Social }\end{array}$ & $\begin{array}{l}\text { - Amizade com atletas e comissão técnica. } \\
\text { - Felicidade e prazer por jogar na equipe. } \\
\text { - Participação em "peladas" e confraternizações nas férias. } \\
\text { - Relação familiar com atletas. }\end{array}$ \\
\hline
\end{tabular}

As características destacadas no Quadro 2 reforçam os resultados encontrados na Tabela 1, visto que as equipes do Campeonato Estadual demonstraram características de alto nível de coesão social e para a tarefa. O Quadro 2 apresenta a caracterização da percepção de coesão de grupo das equipes paranaenses que disputaram a Liga Nacional de Futsal.

De acordo com os dados dispostos no Quadro 3, percebe-se que as equipes participantes da Liga Nacional apresentaram características indicativas de um alto nível de coesão para a tarefa em detrimento da coesão social, além de apresentarem escores inferiores aos das equipes do Campeonato Estadual (Tabela 1). A Tabela 2 apresenta a comparação da percepção dos jogadores sobre o estilo de liderança dos técnicos em função do nível de disputa das equipes de futsal. 
Quadro 2. Caracterização do nível de coesão de grupo das equipes de futsal da Liga Nacional.

\begin{tabular}{|l|l|}
\hline $\begin{array}{l}\text { Dimensões de coesão de } \\
\text { grupo }\end{array}$ & Características \\
\hline $\begin{array}{l}\text { Integração no Grupo- } \\
\text {-Tarefa }\end{array}$ & $\begin{array}{l}\text { - Atletas focados nos mesmos objetivos. } \\
\text { - Trabalho em grupo para o alcance das metas. } \\
\text { - Comemoração de gols em grupo e com a comissão técnica. } \\
\text { - Divisão da responsabilidade por vitórias e derrotas. } \\
\text { - Busca da vitória. }\end{array}$ \\
\hline $\begin{array}{l}\text { Integração no Grupo- } \\
\text {-Social }\end{array}$ & $\begin{array}{l}\text { - Dificuldade de participar de atividades fora de quadra por } \\
\text { causa de viagens e jogos. } \\
\text { - Pouco contato durante as férias em razão de os atletas serem } \\
\text { de diferentes regiões do país. } \\
\text { - Clima saudável e descontraído da equipe. } \\
\text { - Brincadeiras durante os treinos e as viagens. }\end{array}$ \\
\hline $\begin{array}{l}\text { Atração Individual para o o } \\
\text { Grupo-Tarefa }\end{array}$ & $\begin{array}{l}\text { - Participação na Liga Nacional de Futsal. } \\
\text { - Contato e confiança com o treinador. } \\
\text { - Equipe com capacidade para ser campeã. } \\
\text { - Estrutura física e financeira da equipe. } \\
\text { - Vontade de vencer da equipe. }\end{array}$ \\
\hline $\begin{array}{l}\text { Atração Individual para o } \\
\text { Grupo-Social }\end{array}$ & $\begin{array}{l}\text { - Poucos amigos na equipe. } \\
\text { - Eventos fora de quadra não constituem o objetivo principal. } \\
\text { - Pouco contato com os técnicos. }\end{array}$ \\
\hline
\end{tabular}

Tabela 2. Comparação da percepção dos atletas sobre o estilo de liderança dos técnicos em função do nível de disputa das equipes de futsal do estado do Paraná.

\begin{tabular}{|c|c|c|c|c|}
\hline \multirow[t]{2}{*}{ Dimensão } & $\begin{array}{l}\text { Liga Nacional } \\
\qquad(n=65)\end{array}$ & $\begin{array}{l}\text { Campeonato Paranaense } \\
\qquad(n=57)\end{array}$ & \multirow[t]{2}{*}{$p$} & \multirow[t]{2}{*}{ Teste “ $U$ ” } \\
\hline & Md (Q1; Q3) & Md (Q1; Q3) & & \\
\hline Treino-instrução & $4,0(3,7 ; 4,4)$ & $4,5(3,9 ; 4,8)$ & $0,001^{*}$ & 1172,00 \\
\hline Suporte social & $3,5(3,0 ; 4,0)$ & $4,0(3,5 ; 4,5)$ & $0,001 *$ & 1126,50 \\
\hline Reforço & $4,0(3,4 ; 4,4)$ & $4,2(3,7 ; 4,8)$ & $0,021 *$ & 1403,00 \\
\hline Autocrático & $3,0(2,6 ; 3,4)$ & $2,0(1,4 ; 2,8)$ & $0,001^{*}$ & 800,50 \\
\hline Democrático & $3,3(3,0 ; 3,7)$ & $3,7(3,3 ; 4,0)$ & $0,005 *$ & 1304,50 \\
\hline
\end{tabular}

* Diferença significativa $(p<0,05)$.

Conforme se depreende da Tabela 2, ocorreu diferença significativa em todas as dimensões de liderança na percepção dos jogadores sobre o estilo do técnico, evidenciando que os treinadores das equipes da Liga Nacional são mais autocráticos ( $\mathrm{p}=0,001)$, ao passo que os técnicos das equipes do Campeonato Paranaense são mais democráticos $(\mathrm{p}=0,005)$, o que pode ser notado na entrevista do atleta ALN1: "Ah, eu acho que cobra muito, ele tem um estilo de cobranças e de muita dedicação nos treinos e cobra que o jogador renda ao máximo o que puder, vá até o limite. E com isso ele vai ganhar e a equipe vai ganhar".

Por outro lado, os técnicos das equipes do Campeonato Paranaense apresentaram um estilo de liderança mais democrático, conforme relatado pelo atleta ACP11: "Ah, ele é um cara que sabe escutar bastante, que deixa o jogador bem à vontade, que faz com que o time jogue pra ele assim, então ele tem as brincadeiras na hora certa, ele tem a hierarquia dele, sabe comandar bem, então a gente respeita e, ao mesmo tempo, tem uma amizade muito grande, então, fica muito mais fácil que a proposta de jogo seja aceita pelo time, então pelo companheirismo dele a gente acaba jogando por ele". 
Ademais, percebeu-se que os técnicos das equipes do Campeonato Paranaense fornecem mais suporte social $(\mathrm{p}=0,001)$, treino-instrução ( $\mathrm{p}$ $=0,001)$ e reforço $(p=0,021)$ que os técnicos das equipes da Liga Nacional, segundo apontam os dados da Tabela 2. Esse resultado pode ser depreendido da fala do esportista $\mathrm{ACP12:} \mathrm{"Ah,} \mathrm{às} \mathrm{vezes} \mathrm{ele} \mathrm{pede} \mathrm{tempo} \mathrm{no} \mathrm{meio} \mathrm{do}$ jogo, ele conversa com o grupo. Às vezes, ele conversa individual ou com um jogador ou com dois. Mas ele tá sempre apoiando, procurando incentivar pra gente não abaixar a cabeça no decorrer do jogo".

Em contrapartida, os atletas das equipes da Liga Nacional de Futsal consideraram que seus técnicos não fornecem muita instrução, reforço e suporte social no dia a dia, como relata o jogador ALN11: "Depende muito da situação, se é uma situação pra todos, de repente ele corrige um que vai servir pra todos, de repente já é uma correção individual, não é um erro da equipe, mas normalmente é sempre o lado da equipe, ele fala pra um e éo que vale pra todos".

Nesse contexto, a caracterização do estilo de liderança dos técnicos das equipes do Campeonato Estadual e da Liga Nacional de Futsal é apresentada no Quadro 3.

Quadro 3. Caracterização dos antecedentes do estilo de liderança dos técnicos das equipes de futsal da Liga Nacional e do Campeonato Estadual.

\begin{tabular}{|c|c|c|c|}
\hline Grupos & Categorias & Antecedentes & Características \\
\hline \multirow[t]{3}{*}{ Liga Nacional } & \multirow[t]{3}{*}{$\begin{array}{l}\text { Liderança } \\
\text { do técnico }\end{array}$} & $\begin{array}{l}\text { Características } \\
\text { do líder }\end{array}$ & $\begin{array}{l}\text { - Exigente. } \\
\text { - Competitivo. } \\
\text { - Passa confiança e segurança para o grupo. }\end{array}$ \\
\hline & & $\begin{array}{l}\text { Características } \\
\text { da situação }\end{array}$ & $\begin{array}{l}\text { - Boa infraestrutura. } \\
\text { - Salários pagos em dia. } \\
\text { - Falta de patrocinador. } \\
\text { - Diretoria competente. } \\
\text { - Atletas em boa condição física. }\end{array}$ \\
\hline & & $\begin{array}{l}\text { Características } \\
\text { dos atletas }\end{array}$ & $\begin{array}{l}\text { - Concentração nos treinamentos. } \\
\text { - Envolvimento com as metas da equipe. } \\
\text { - Dedicação em prol da equipe. } \\
\text { - Competitividade. } \\
\text { - Desejo de melhora do desempenho. }\end{array}$ \\
\hline \multirow[t]{3}{*}{$\begin{array}{l}\text { Campeonato } \\
\text { Paranaense }\end{array}$} & \multirow[t]{3}{*}{$\begin{array}{l}\text { Liderança } \\
\text { do técnico }\end{array}$} & $\begin{array}{l}\text { Características } \\
\text { do líder }\end{array}$ & $\begin{array}{l}\text { - Deixa os jogadores à vontade para jogar. } \\
\text { - Companheiro e amigo dos atletas. } \\
\text { - Passa confiança e segurança para o grupo. } \\
\text { - Inteligente. } \\
\text { - Apoia e incentiva sempre o grupo. }\end{array}$ \\
\hline & & $\begin{array}{l}\text { Características } \\
\text { da situação }\end{array}$ & $\begin{array}{l}\text { - Salários pagos em dia. } \\
\text { - Boa infraestrutura. } \\
\text { - Atletas em boa condição física. } \\
\text { - Diretoria competente. }\end{array}$ \\
\hline & & $\begin{array}{l}\text { Características } \\
\text { dos atletas }\end{array}$ & $\begin{array}{l}\text { - Companheirismo com demais atletas. } \\
\text { - Envolvimento com as metas da equipe. } \\
\text { - Dedicação em prol da equipe. } \\
\text { - Amizade com atletas e comissão técnica. } \\
\text { - Desejo de melhora do desempenho. }\end{array}$ \\
\hline
\end{tabular}

Além das diferenças encontradas na Tabela 2 e das características citadas por meio dos depoimentos dos atletas e técnicos, nota-se no Quadro 3 que algumas características dos atletas e da equipe podem influenciar 
ou estar relacionadas com o comportamento do técnico. Mediante análise dos dados do Quadro 3, percebe-se que os dois grupos dispunham de boa infraestrutura física e financeira, entretanto, as equipes do Campeonato Estadual não possuíam muitos patrocinadores. Outro aspecto interessante está relacionado às características dos atletas, uma vez que os jogadores da Liga Nacional estavam totalmente envolvidos com as metas da equipe e buscavam mais o sucesso esportivo, se comparados aos atletas das equipes do Campeonato Estadual, que, além do foco na tarefa, também apresentaram características sociais, como amizade e companheirismo com atletas e comissão técnica.

\section{DISCUSSÃO}

De acordo com os resultados da pesquisa bibliográfica empreendida, este é o primeiro estudo na literatura a avaliar o nível de coesão de grupo e o estilo de liderança de treinadores de equipes de futsal de alto rendimento em função do nível competitivo (estadual/nacional), além de utilizar uma análise quantitativa e qualitativa para discussão dos resultados. No presente estudo, observou-se que as equipes participantes da competição de menor expressão (Campeonato Paranaense) apresentaram maior nível de coesão de grupo na maioria das dimensões (Tabela 1), técnicos mais democráticos e que forneciam mais instruções, reforço e suporte social aos atletas (Tabela 1). Por outro lado, os técnicos das equipes da Liga Nacional possuíam estilo mais autocrático (Tabela 2). Todos esses resultados foram confirmados pelos depoimentos de jogadores e técnicos e pela categorização das entrevistas (Quadros 1, 2 e 3).

Percebeu-se que os times que disputavam a competição de nível inferior demonstraram estar mais unidos e integrados para a busca e o alcance das metas se comparados às equipes da Liga Nacional (Tabela 1), o que pode estar relacionado ao fato de os atletas profissionais buscarem união quando se encontram em situações adversas ou ainda, quando almejam objetivos maiores na carreira esportiva. Esse achado vai ao encontro de um estudo ${ }^{21} \mathrm{com}$ jogadores adultos de futsal, no qual se verificou que equipes com pior classificação em uma competição ou de nível inferior tendem a se unir para superar situações adversas e alcançar objetivos maiores dentro de uma competição.

Por outro lado, Narimani e Ahari ${ }^{9}$ verificaram, em um estudo com diferentes modalidades esportivas, que esportistas campeões apresentam maior nível de coesão de grupo em detrimento dos atletas não campeões, evidenciando que atletas com maior sucesso esportivo possuem melhor coesão de grupo. Outro estudo com atletas de basquetebol do campeonato nacional turco avaliou a coesão de grupo antes e depois da temporada, verificando que jogadores que obtiveram sucesso durante o ano apresentaram maior nível de coesão de grupo ${ }^{12}$. No presente estudo, os times de nível inferior (estadual) apresentaram maior nível de coesão de grupo que os de nível nacional, entretanto, as equipes da Liga Nacional obtiveram, tam- 
bém, altos níveis de coesão para a tarefa, característica que é fundamental para o sucesso esportivo (Tabela 1), achado que pode estar relacionado ao fato de que mesmo equipes profissionais de diferentes níveis competitivos apresentam maior foco para a tarefa.

A coesão para a tarefa é, neste contexto, um elemento fundamental para a satisfação de equipes esportivas dentro de uma competição $0^{22}$, visto que, quanto maior o envolvimento dos atletas com as metas da equipe, mais ficarão satisfeitos e, consequentemente, melhor poderá ser o desempenho esportivo da equipe ${ }^{1,14}$. Assim, nota-se que a interação entre os integrantes de uma equipe é um elemento que influencia a confiança para atingir metas importantes, ressaltando que a satisfação e a coesão de grupo são fatores de extrema importância para que uma equipe esportiva alcance $o$ sucesso $^{4,15,23}$. Dessa forma, percebe-se, no presente estudo, que ambos os grupos (Paranaense e Liga Nacional) apresentaram os maiores níveis de coesão nas dimensões da tarefa, achado que vai ao encontro da literatura ${ }^{1,5}$.

Observou-se diferença significativa também na dimensão Atração Individual para o Grupo-Social, na qual as equipes participantes apenas do Campeonato Paranaense apresentaram maiores escores, indicando que esse grupo possui melhor percepção em relação aos sentimentos individuais dos membros sobre seu envolvimento pessoal, aceitação e interação social com os demais jogadores ${ }^{13,24}$. Esse resultado destaca que integrantes de equipes de nível inferior e que viajam menos para disputa de competições podem se envolver e buscar maior interação social com os demais atletas. Esse resultado corrobora os encontrados por Nascimento Junior, Souza e Vieira ${ }^{21}$, cujo estudo apontou que equipes de futsal de nível inferior ou com pior classificação em uma competição apresentam maior atração individual para o grupo-social em detrimento das equipes mais bem qualificadas.

Dessa forma, a literatura assinala que o envolvimento individual do atleta com a coesão social da equipe também é um fator importante para o sucesso esportivo ${ }^{5,13}$, uma vez que a coesão social também favorece a melhora do desempenho esportivo, além de incentivar o atleta a continuar na equipe nas temporadas seguintes ${ }^{25}$. No entanto, a coesão social de uma equipe não pode ser muito mais alta que a coesão para a tarefa, uma vez que o excesso de envolvimento social entre os atletas pode diminuir o foco em relação aos objetivos e às metas do grupo ${ }^{26}$.

Ao comparar a percepção dos atletas sobre o estilo de liderança dos técnicos em função do nível de disputa das equipes de futsal, verificou-se que os técnicos dos times do Campeonato Paranaense forneciam mais instruções, reforço e suporte social aos atletas em comparação com os técnicos das equipes da Liga Nacional. Esse resultado coincide com o apresentado em um estudo ${ }^{27}$ com atletas universitários canadenses considerados talentosos e não talentosos. Nesse estudo, atletas talentosos consideraram as dimensões "treino-instrução" e "reforço" menos utilizadas pelos técnicos em comparação com os atletas não talentosos. Resultado semelhante também foi encontrado em um estudo com jogadores jovens e profissionais de handebol, evidenciando que atletas novatos percebem 
que seus treinadores fornecem mais instruções e reforço em comparação com atletas experientes ${ }^{28}$.

Os técnicos das equipes da Liga Nacional de Futsal eram mais autocráticos, ao passo que os técnicos dos times do Campeonato Paranaense eram mais democráticos, resultados que foram confirmados pelos depoimentos dos futebolistas, evidenciando que quanto maior o nível competitivo da equipe e a pressão por vitórias, mais autocrático e voltado para a tarefa é o estilo de liderança do treinador. Costa, Samulski e Costa ${ }^{29}$ chegaram a resultados semelhantes em uma pesquisa com técnicos do Campeonato Brasileiro de Futebol, observando que técnicos de equipes de alto rendimento apresentam estilo de liderança mais autocrático.

Sobre o estilo de liderança dos técnicos, a literatura aponta que técnicos devem prestar atenção no estilo de liderança adotado perante os atletas, visto que a liderança autoritária parece aumentar mais a probabilidade de burnout que os outros estilos ${ }^{3,6}$. Um treinador deve ser sensível à especificidade da situação e do envolvimento com os jogadores ${ }^{29}$, uma vez que diferentes situações requerem diferentes atuações de liderança ${ }^{30}$. No presente estudo, embora os integrantes das equipes da Liga Nacional tenham relatado que seus técnicos eram mais autocráticos durante os treinamentos e os jogos, os jogadores também apontaram que o comportamento do treinador era influenciado pelas diferentes situações durante a competição, o que confirma os resultados disponíveis na literatura a respeito, evidenciando que as características do contexto esportivo são elementos intervenientes no estilo de liderança adotado pelo treinador.

\section{CONCLUSÃO}

Por meio dos resultados encontrados, conclui-se que os técnicos das equipes da Liga Nacional de Futsal apresentaram estilo de liderança mais autocrático que os técnicos das equipes do Campeonato Paranaense. Esses achados indicam que, no contexto esportivo profissional e de alto rendimento, os técnicos focam-se essencialmente na busca das vitórias e do sucesso. Ressalta-se, ainda, que as características de suporte social, reforço e instruções durante os treinamentos e jogos e o estilo democrático são mais frequentes em técnicos de equipes de nível inferior (Campeonato Paranaense). As equipes participantes do Campeonato Estadual apresentaram maior coesão para a tarefa quando comparadas com as equipes da Liga Nacional.

Como limitações, destaca-se que não podemos generalizar os resultados para toda a realidade brasileira, uma vez que foram avaliadas apenas equipes do estado do Paraná, entretanto, foram selecionadas as principais equipes do estado e que integram o ranking nacional. Outra limitação consiste no fato de não se ter avaliado as equipes durante a temporada, impossibilitando verificar se o desempenho durante a temporada pode influenciar o nível de coesão de grupo e o estilo de liderança das equipes de futsal.

Diante disso, pesquisas envolvendo equipes de alto rendimento de diferentes níveis competitivos (estadual, nacional e internacional) e regi- 
ões do Brasil podem avançar em relação aos achados do presente estudo, possibilitando a generalização dos resultados para o contexto esportivo do futsal brasileiro. Trabalhos com outras modalidades esportivas e com atletas do gênero feminino também são importantes para o avanço nas pesquisas sobre coesão de grupo e liderança de técnicos.

\section{REFERÊNCIAS BIBLIOGRÁFICAS}

1. Carron AV, Colman MM, Wheeler J, Stevens D. Cohesion and performance in sport: A meta-analysis. J Sport Exerc Psychol 2002;24:168-88.

2. Halbrook M, Blom LC, Hurley K, Bell RJ, Holden J. E. Relationships among motivation, gender, and cohesion in a sample of collegiate athletes. J Sport Behav 2012;35(1):61-77.

3. Vincer DJE, Loughead TM. The relationship among athlete leadership behaviors and cohesion in team sports. The Sport Psychologist 2010;24(4):448-67.

4. Carron AV, Eys MA, Burke SM. Team cohesion: nature, correlates, and development. In. Jowett S, Lavallee D, editor. Social psychology in sport. Champaign, IL: Human Kinetics, 2007. p. 91-102.

5. Carron AV, Hausenblas HA, Eys MA. Group Dynamics in Sport. Morgantown, WV: Fitness Information Technology; 2005.

6. Chelladurai P. Handbook of Sport Psychology. In. Tenembaum G, Eklund R, editor. Leadership in Sports. New Jersey: Wiley. 2007. p. 113-135.

7. Jowett $S$, Chaundy V. An investigation into the impact of coach leadership and coach-athlete relationship on group cohesion. Group Dynamics: Theory, Research and Practice 2005;8(4):302-11.

8. Aoyagi MW, Cox RH, Mcguire RT. Organizational citizenship behavior in sport: relationships with leadership, team cohesion, and athlete satisfaction. J Appl Sport Psych 2008;20(1):25-34.

9. Narimani M, Ahari SS. A study of the relationship between team cohesion, role ambiguity and athletic performance in football team players. Res J Biolog Sci 2008; 3(1):47-51.

10. Ramzaninezhad R, Keshtan MH. The relationship between coach's leadership styles and team cohesion in iran football clubs professional league. Brazilian J Biom 2009;3 (2):111-120.

11. Heydarinejad S, Adman O. Relationship between coaching leadership styles and team cohesion in football teams of the Iranian university league. Studies in physical culture and tourism 2010;17(4):367-72.

12. Toros T. Analysis the differentiation between perceived coaching behaviors, goal orientation, team cohesion, perceived motivational climate and collective efficacy among the young male basketball players before and after the tournament. $\mathrm{Pa}-$ mukkale J Sport Sci 2011;2(1):27-39.

13. Carron AV, Brawley LR, Widmeyer WN. The development of an instrument to measure cohesion in sport teams: The Group Environment Questionnaire. J Sport Exerc Psychol 1985;7:244-66.

14. Chiocchio F, Essiembre H. Cohesion and performance: a meta-analytic review of disparities between project teams, production teams, and service teams. Small Group Research 2009;40:382-420.

15. Nascimento Junior JRA, Vieira F, Sousa EA, Vieira JLL. Nível de satisfação do atleta e coesão de grupo em equipes de futsal adulto. Rev Bras Cineantropom Desempenho Hum 2011;13(2):138-44.

16. Nascimento Junior, JRA. Estudo da validação do Questionário de Ambiente de Grupo e sua relação com a liderança no contexto esportivo competitivo. 2011. Dissertação (Mestrado em Educação Física). Centro de Ciências da Saúde. Universidade Estadual de Maringá, Maringá, 2011. 
17. Eys MA, Carron AV, Bray SR, Brawley LR. Item wording and internal consistency of a measure of cohesion: The Group Environment Questionnaire. J Sport Exerc Psychol 2007;29:395-402.

18. Chelladurai P, Saleh SD. Prefered leadership in sports. Can J Appli Sci. 1978; 3: 85-92.

19. Serpa S, Pataco V, Santos F. Leadership patterns in Handball international competition. Int J Sport Psychol 1991;22:78-89.

20. Bardin L. Análise de conteúdo. São Paulo: Edições 70, 2008.

21. Nascimento Junior JRA, Souza EA, Vieira LF. Avaliação da percepção de coesão de grupo de equipes profissionais de futsal do Estado do Paraná. EFDeportes.com, Revista Digital 2010;15(151):1-7.

22. Spink K S, Nickel D, Wilson K, Odnokon P. Using a multilevel approach to examine the relationship between task cohesion and team task satisfaction in elite ice hockey players. Small Group Research 2005;36:539-55.

23. Karreman E, Dorsch K, Riemer H. Athlete Satisfaction and Leadership: Assessing Group-Level Effect. Small Group Research 2009;40(6):720-37.

24. Eys MA, Hardy J, Carron AV, Beauchamp MR. The relationship between task cohesion and competitive state anxiety. J Sport Exerc Psychol 2003;25:66-76.

25. Nathan S, Birouste AB, Evers C, Kemp L, Mackenzie J, Henley R. Social cohesion through football: a quasi-experimental mixed methods design to evaluate a complex health promotion program. BMC Public Health 2010;10:587-90.

26. Hardy J, Eys MA, Carron AV. Exploring the Potential Disadvantages of High Cohesion in Sports Teams. Small Group Research 2005;36:166-88.

27. Beauchamp MR, Bray SR, Fielding A, Eys MA. A multilevel investigation of the relationship between role ambiguity and role efficacy in sport. Psych Sport Exerc 2005; 6(3):289-302.

28. Gomes AR, Paiva P. Liderança, compatibilidade treinador-atleta e satisfação no andebol: percepção de atletas novatos e experientes. Psico-USF 2010;15(2):235-48.

29. Costa IT, Samulski DM, Costa VT. Perfil de liderança para treinadores de futebol na visão de treinadores do campeonato brasileiro. Rev Educ Fís/UEM 2010;21(1):59-68.

30. Crust L, Lawrence I. A Review of Leadership in Sport: Implications for Football Management. Athletic Insight 2006;8(4):29-48.
Endereço para correspondência

José Roberto Andrade do Nascimento Junior

Rua Tietê, 614, Apto. 05 ,

Jardim Universitário, CEP-87020-210,

Maringá, PR. Brasil.

E-mail: junior_jrs001@hotmail.com 